\title{
Understanding Timber Stairs with Video-based Learning: An Empirical Study in University Students
}

\author{
Nurlylia Binti Rohizir ${ }^{1}$, Jumintono ${ }^{1, *}$, Dyah Erni Widyastuti ${ }^{2}$, Firdaus Yuni Dharta ${ }^{3}$, Mei Tri Sundari ${ }^{4}$, \\ Indra Perdana ${ }^{5}$, Niko Azhari Hidayat ${ }^{6}$, Husin Rayesh Mallaleng ${ }^{7}$, Roma Tao Toba $^{8}$, \\ Judi Januadi Endjun', Anastasia Riani Suprapti ${ }^{10}$
}

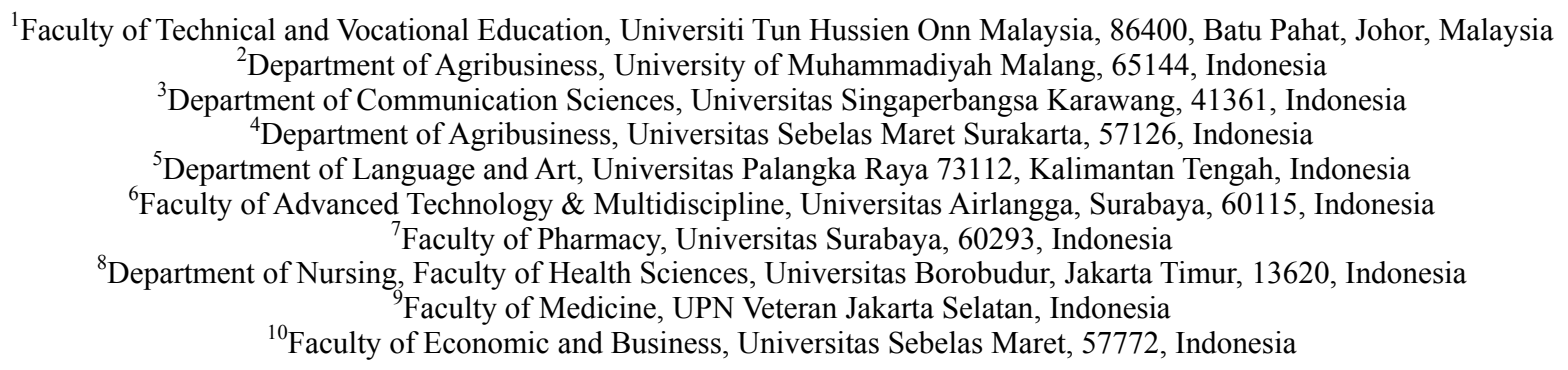

Received August 30, 2020; Revised November 7, 2020; Accepted November 19, 2020

\section{Cite This Paper in the following Citation Styles}

(a): [1] Nurlylia Binti Rohizir, Jumintono, Dyah Erni Widyastuti, Firdaus Yuni Dharta, Mei Tri Sundari, Indra Perdana, Niko Azhari Hidayat, Husin Rayesh Mallaleng, Roma Tao Toba, Judi Januadi Endjun, Anastasia Riani Suprapti , "Understanding Timber Stairs with Video-based Learning: An Empirical Study in University Students," Universal Journal of Educational Research, Vol. 8, No. 12B, pp. 8017-8021, 2020. DOI: 10.13189/ujer.2020.082602.

(b): Nurlylia Binti Rohizir, Jumintono, Dyah Erni Widyastuti, Firdaus Yuni Dharta, Mei Tri Sundari, Indra Perdana, Niko Azhari Hidayat, Husin Rayesh Mallaleng, Roma Tao Toba, Judi Januadi Endjun, Anastasia Riani Suprapti (2020). Understanding Timber Stairs with Video-based Learning: An Empirical Study in University Students. Universal Journal of Educational Research, 8(12B), 8017-8021. DOI: 10.13189/ujer.2020.082602.

Copyright $\mathrm{C} 2020$ by authors, all rights reserved. Authors agree that this article remains permanently open access under the terms of the Creative Commons Attribution License 4.0 International License

\begin{abstract}
Timber stairs are defined as a series of wood steps to connect different floors in the room. This study aims to look at the level of understanding of timber stairs among architecture students. Second, this study aims to help students understand timber stairs intensively with the video's help. This wooden ladder is part of a wooden construction known as basic knowledge but is rarely considered relevant. Therefore, this quantitative research was used to find the benefits of using video in explaining timbers stairs to students. A set of objective questions with many choices were used as instruments in this study. The topic of timber stairs has been found in Construction Technology subjects for students of the UiTM Series Iskandar for their Bachelor of Architecture degree in semester 2 . The sample used consisted of 25 students from the UiTM Series Iskandar. A total of 25 respondents have been taken to answer the pre-test questions before watching the video and post-test, which must be answered by them after watching the video. Data were analyzed using SPSS
\end{abstract}

with very positive results. The findings show that most architecture students know timber stairs, but their understanding is not 100 percent correct. The conclusion shows that using video as a learning medium does help students to understand the Timbers ladder.

Keywords Timber Stairs, Video-based Learning, Empirical Study, University Students

\section{Introduction}

Technical and Vocational Training is established for geared up the workforce to accomplish job duty. This research was conducted to help architecture students understand Timbers stairs' basic knowledge intensively with video-based learning. At present, the timber market is overgrowing because it has a $57 \%$ stake in the Malay 
houses in Malaysia. The wood industry plays a vital role in development, especially for the housing sector. The challenge in the timber market today is how to control climate change by reducing $\mathrm{CO}^{2}$ emissions in the production of building materials [1]. Mitigation of global warming is used as a key to developing strategies for the built environment and sustainable policies of developed countries to reduce carbon emissions [2]. According to [3], greenhouse gas emissions have become one of the biggest environmental problems in society today, causing wood used as structural building materials to become a market that is growing and developing quite rapidly. By the opinion [4], this growth is partly due to wood's carbon sequestration ability and its contribution to sustainable development. Besides, the wood market's rapid growth is also expected because it has advantages in the life cycle and has economic benefits that are more profitable than conventional buildings [5]. This construction makes wood a powerful competitor for other traditional construction forms such as bricks and beams. The popularity of wood is increasing due to efficient off-site fabrication and demonstrated capacity to reduce the effects of Carbon Dioxide $\left(\mathrm{CO}^{2}\right)$ with wood-based solutions. The active role of natural materials, such as wood, is to approach architectural achievements that are truly holistic and sustainable that actively and performatively consider their environmental impacts [6].

Interdependence between carbon storage and material efficiency is proven to occur in buildings made of wood [7]. Because wood is the only building material that can be grown, so it has a natural tendency that wood building materials are perfect for the environment [8]. As a construction, wood through its short tree life cycle and the benefits of carbon sequestration are relatively high, increasingly seen as a sustainable building system that has begun to be maintained in many areas [9]. Renovation and expansion of existing buildings with wood construction can contribute significantly to sustainable city development [10]. Wood has been used as a critical element in the structure. Timber construction has also been used since ancient times and to this day as a low-cost structural foundation [11]. Wood applications have varied from structural frames to facade surfaces. At present, various alternative materials can be combined; for example, it is possible to combine wood with other materials, such as stainless steel, glass, stone, and fiberglass [12]. Research conducted by [13], Timber-Concrete-Composite (TCC) systems have increasingly been used in recent decades. One of the main reasons for this TCC is related to applications that cannot be built with wood alone but have become possible with the TCC solution. Perspectives and examples come from Europe, North America, and Oceania to provide a worldwide perspective of the region where the TCC system is used, including bridges and floors in public buildings. For each project, details of the application are presented, and the way each contributes to expanding the use of wood in construction.

Since 2006, the Center for Advanced Wood Concept Research (ATC) has been developing innovative approaches to design with wood at various scales. Through teaching-based research and applied research in a professional context, the research group has engaged in cutting-edge practices uniquely relevant to Australian wood culture while engaging with digital wood design in a global context. Projects carried out since 2006 include a ten-year project running an intensive furniture design course at the university. The project focuses on re-imagining the role of low-value wood in furniture making, using traditional techniques and digital fabrication

Computer-Sophisticated-Manufacturing sophisticated processes.

This strategic research and development have supported wood construction to be built up to 6-story construction. Based on the information above, wood construction is essential and should not be taken lightly by all architects, engineers, contractors, and all related fields in the future. Therefore, architecture students must master wood construction for their future provision. Despite the achievements of wood construction, certain parts of wood known as stairs are often ignored. Stairs are an integral part of most buildings. It is subject to the same principles and technological constraints as other building structures [14]. The structural design of the stairs is separate from the design and realization of residential buildings. Stair designs need to be dealt with in terms of static, fire safety, layout requirements, and in the case of wood-based buildings [15]. Requirements, specifications, and characteristics of the stairs will impact the sound source and sound pressure borne by the building structure [16].

Timbers stairs are divided into two types, known as an open stringer and closed staircase stringer. The closed stringer ladder has a wooden board with a height side covering the riser and thread from the bottom of the ladder. Furthermore, an open stringer ladder is a riser, and the line can be seen clearly from all heights, similar to a typical standard ladder. Joints used for timber stairs are known as "mortise." The connection between the thread and the riser is usually not fixed, and many variables can change in the connection section. The stairs' surface needs to be supported by the Bearer of the upper floor to balance the ladder to not fall out of place. Besides, floor beams can also be supported, depending on wood construction on the first floor [17].

The information mentioned above will be easier to understand with pictures or other videos to help students understand it better. Video in education is possible to overcome the obstacles that exist in the world of education. Video-based learning is efficient and able to explore the digital world's greater possibilities [18]. The use of video in education continues to increase during recent years as one of the cores in educational resources' openness [19]. Learners have described video-based 
teaching as a fun, satisfying, motivating, and useful learning medium for enhancing learning [20]. The use of video has a significant influence on teaching and learning practices in the classroom. It is recommended that the video can be adopted to enhance teacher professional development [21]. That is one of the importance of using a video as a learning medium in this study so that timber stairs will be more readily understood through direct practice and technological intelligence.

Wood construction is one of the subjects that will be studied by architecture students at the university level. However, individual studies on Timbers stairs are often overlooked by most students because it is difficult to understand theory with explanations in class alone. The wood construction lecturer always hopes students understand the method by reading and skipping answers about timber stairs in the classroom. The importance of this research is to determine students' understanding of architecture on Timbers stairs. This study was conducted to measure students' knowledge in the classroom by using videos explaining the timber stairs theory and videos and timber stairs' pictures. No less important, this study ensures that architecture students understand the basis of Timbers stairs at the end of this study.

\section{Materials and Methods}

The study was conducted using a quantitative research approach. Quantitative research is data collected in digital content. This design was chosen because it was considered suitable for use in reviewing and analysing for understanding timber stairs among students' architectural education. This study's target population is architecture students at the architecture school at UiTM Seri Iskandar,
Perak in Malaysia, totalling 25 students. Samples of 25 architectural students were collected from pre and post-tests conducted and tested because they had learned about Timbers' stairs in their wood construction subject. A set of objective questions with several answer choices was being used as instruments. This study uses six problems in the timbers ladder (a series of stairs connecting the various floors in the room). Students must answer all questions for matters before the test. After watching videos made to understand timber stairs better, they need to answer the post-test questions. The difference between pre and post-tests can be seen through the order of items. Questionnaires are collected via Google forms on the online web. Data were calculated into SPSS to find the frequency and percentage of students' answers to architecture.

\section{Findings and Discussion}

Respondent demographics are general information containing gender and age. The demographics of respondents can be seen in table 1 .

Table 1. Respondent demographics

\begin{tabular}{|c|c|c|c|c|}
\hline No. & Demographics & Description & Frequency & Percentage \\
\hline \multirow{3}{*}{1} & \multirow{2}{*}{ Gender } & Male & 5 & 20 \\
\cline { 2 - 5 } & & Female & 20 & 80 \\
\cline { 2 - 5 } & \multicolumn{2}{|c|}{ Total } & 25 & 100 \\
\hline \multirow{3}{*}{2} & \multirow{2}{*}{ Age } & 19 & 15 & 60 \\
\cline { 2 - 5 } & \multicolumn{2}{|c|}{ Total } & 10 & 40 \\
\cline { 2 - 5 } & \multicolumn{2}{|c|}{20} & 25 & 100 \\
\hline
\end{tabular}

The results of the pre-test and post-test on the given questionnaire can be seen in table 2

Table 2. The results of the pre-test and post-test on understanding the Timber Ladder

\begin{tabular}{|c|c|c|c|c|c|c|}
\hline \multirow{2}{*}{ No. } & \multirow{2}{*}{ Question } & \multirow{2}{*}{$\begin{array}{l}\text { Respondent's } \\
\text { Answer }\end{array}$} & \multicolumn{2}{|c|}{ Pre-Test } & \multicolumn{2}{|c|}{ Post-Test } \\
\hline & & & Frequency & Percentage & Frequency & Percentage \\
\hline \multirow{3}{*}{1} & \multirow{3}{*}{$\begin{array}{l}\text { Which one of the answers below is the } \\
\text { type of timber stairs? }\end{array}$} & Right & 5 & 20.0 & 5 & 20.0 \\
\hline & & Wrong & 20 & 80.0 & 20 & 80.0 \\
\hline & & Total & 25 & 100.0 & 25 & 100.0 \\
\hline \multirow{3}{*}{2} & \multirow{3}{*}{$\begin{array}{l}\text { What is the type of timber stairs shown } \\
\text { below? }\end{array}$} & Right & 0 & 0 & 20 & 80.0 \\
\hline & & Wrong & 25 & 100.0 & 5 & 20.0 \\
\hline & & Total & 25 & 100.0 & 25 & 100.0 \\
\hline \multirow{3}{*}{3} & \multirow{3}{*}{$\begin{array}{l}\text { What is the type of timber stairs shown } \\
\text { below? }\end{array}$} & Right & 0 & 0 & 20 & 80.0 \\
\hline & & Wrong & 25 & 100.0 & 5 & 20.0 \\
\hline & & Total & 25 & 100.0 & 25 & 100.0 \\
\hline \multirow{3}{*}{4} & \multirow{3}{*}{$\begin{array}{c}\text { The surface of the stairs on the first-floor } \\
\text { level needs to be supported? }\end{array}$} & Right & 5 & 20.0 & 20 & 80.0 \\
\hline & & Wrong & 20 & 80.0 & 5 & 20.0 \\
\hline & & Total & 25 & 100.0 & 25 & 100 \\
\hline \multirow{3}{*}{5} & \multirow{3}{*}{$\begin{array}{l}\text { What is the joint used to connect the } \\
\text { timber structures without using screws, } \\
\text { nails, or glue? }\end{array}$} & Right & 4 & 16 & 20 & 40 \\
\hline & & Wrong & 21 & 84 & 5 & 60 \\
\hline & & Total & 25 & 100.0 & 25 & 100.0 \\
\hline \multirow{3}{*}{6} & \multirow{3}{*}{$\begin{array}{c}\text { What is the difference between Opened } \\
\text { Stringer Stairs and Closed Stringer } \\
\text { Stairs? }\end{array}$} & Right & 15 & 60.0 & 25 & 100.0 \\
\hline & & Wrong & 10 & 40.0 & 0 & 0 \\
\hline & & Total & 25 & 100.0 & 25 & 100.0 \\
\hline
\end{tabular}


Question number one, the pre-test results showed five students answered the questions correctly, and 20 students answered incorrectly. The post-test results showed no improvement in answers. So that video-based learning does not affect student knowledge. This question is made to test students' basic understanding of whether they know the timbers ladder-type or not. The answer to this question is A for Open Stringer stairs, and the other solution is a concrete ladder type.

Question number two, the Pre-Test result, showed that all students answered the question incorrectly. The Post-Test results showed an improvement where 20 out of 25 students could answer the questions correctly after watching the timber ladder video. The second question shows a picture of a closed zinc ladder, but the answer options vary, which can be confusing. This question was created to test students' knowledge of a wooden ladder known as a final note.

Question number three, the pre-test results show that all respondents answered incorrectly. The results of the Post-Test show the results of the increase in respondents' answers, where 20 students answered correctly, and five students answered incorrectly. After watching the learning video, the percentage of correct responses shows $80 \%$ correct answers and 20\% incorrect answers. The third question provides knowledge about the types of wooden ladders commonly used.

Question number four, the pre-test result showed five students answered correctly, and 20 students answered incorrectly. Post-Test results show an increase in students' correct answers. Students answered correctly to 20 people with a percentage of $80 \%$, and $20 \%$ answered incorrectly. The post-test results show that video-based learning can improve students' understanding of stairs on the first floor.

Question number five, the Pre-Test result, showed four students answered correctly, and 21 students answered incorrectly with a percentage of $16 \%$ of the answers were correct, and $84 \%$ of the answers were wrong. The results of the Post-Test showed an increase in students' understanding of the joints used to join wooden structures without using screws, nails, and glues. The Post-Test result showed the percentage of correct answers is $80 \%$, and incorrect answers are $20 \%$. Based on question number five, video-based learning can improve student understanding.

Question number six, the Pre-Test result, showed 15 students answered correctly, and ten students answered incorrectly. Post-Test results show an increase in student answers, where $100 \%$ of students answered correctly. These results indicate that video-based learning can increase students' knowledge about the different types of timber ladders.

The pre-test and post-test results for all questions increased the correct answer, except for one item, namely question number one. Based on these results, video-based learning can be applied in class. Video-based learning helps students understand the timber ladder topic much better than learning the theory itself in class.

\section{Conclusions}

In conclusion, timber stairs must be recognized by architecture students even they have difficulty understanding the theory. Therefore, with the help of a video about timber stairs, architecture students can better understand it. Interactive videos also have an impact on the emotional side of student behavior. They can increase attention to the lecture subject and positively affect students in improving motivation [22]. Timbers stairs are also unique to explore because we can still see timber stairs in most traditional Malay houses in Malaysia. Most of them will use a wooden ladder at their front door to connect the raised floor to the groove. Through this study, researchers can find the difference between the Pre-tests and Post-tests that have been conducted on a sample of architectural students from the UiTM Series Iskandar, Perak. Most of the questions answered by them are responded to better in the post-test after watching the video, and there are still some questions that confuse them to answer them wrong in the post-test but right in the pre-test found may be video weaknesses. The limitation of the study is taken from only the students at one level with the limited respondents. Further studies on making useful wooden stair videos that can help students overcome confusion will be an excellent recommendation to do in the future.

\section{REFERENCES}

[1] A. Fadai, M. Fuchs, and W. Winter, 'Wood-Based Construction for Multi-story Buildings: Application of Cement Bonded Wood Composites as Structural Element', RILEM Bookseries, vol. 9, pp. 471-484, 2014.

[2] A. K. Bin Marsono and A. T. Balasbaneh, 'Combinations of building construction material for residential building for the global warming mitigation for Malaysia', Constr. Build. Mater., vol. 85, pp. 100-108, Jun. 2015.

[3] D. Hedberg, S. Kullander, and H. Frank, 'The World Needs a New Energy Paradigm', Ambio, vol. 39, no. SPEC. 1, pp. 110, Jul. 2010.

[4] A. Gosselin, P. Blanchet, N. Lehoux, and Y. Cimon, 'Collaboration Enables Innovative Timber Structure Adoption in Construction', Buildings, vol. 8, no. 12, Dec. 2018 .

[5] M. Sandanayake, W. Lokuge, G. Zhang, S. Setunge, and Q. Thushar, 'Greenhouse Gas Emissions During Timber and Concrete Building Construction -A Scenario Based Comparative Case Study', Sustain. Cities Soc., vol. 38, pp. 91-97, Apr. 2018.

[6] P. Beale and T. Morgan, 'Advanced timber concepts and the design of furniture and structures', in Lecture Notes in Civil 
Engineering, vol. 24, Springer, 2019, pp. 159-194.

[7] A. Hafner and S. Schäfer, 'Environmental Aspects of Material Efficiency Versus Carbon Storage in Timber Buildings', Eur. J. Wood Wood Prod., vol. 76, no. 3, pp. 1045-1059, May 2018.

[8] M. H. Ramage et al., 'The wood from the trees: The use of timber in construction', Renew. Sustain. Energy Rev., vol. 68, pp. 333-359, Feb. 2017.

[9] U. Y. A. Tettey, A. Dodoo, and L. Gustavsson, 'Effect of Different Frame Materials on the Primary Energy use of a Multi Storey Residential Building in a Life Cycle Perspective', Energy Build., vol. 185, pp. 259-271, Feb. 2019.

[10] T. Schuetze, 'Wood Constructions for Sustainable Building Renovation', Adv. Mater. Res., vol. 1150, pp. 67-72, Nov. 2018.

[11] A. Bukauskas et al., 'Whole timber construction: A state of the art review', Constr. Build. Mater., vol. 213, pp. 748-769, Jul. 2019.

[12] J. Pěnčík, M. Lavický, P. Král, and Z. Havířová, 'Analysis of Behaviour of Prefabricated Staircases with One-Sided Suspended Stairs', Drv. Ind., vol. 66, no. 2, pp. 147-156, Jul. 2015.

[13] A. Dias, J. Skinner, K. Crews, and T. Tannert, 'Timber-concrete-composites Increasing the use of Timber in Construction', Eur. J. Wood Wood Prod., vol. 74, no. 3, pp. 443-451, May 2016.

[14] L. Vesela, 'Staircase - Dimensions of Stair Steps and their Deviations of Geometrical Accuracy', IOP Conf. Ser. Mater.
Sci. Eng., vol. 471, no. 2, p. 022012, Feb. 2019.

[15] B. Kovarova, 'Use of Prefabrication in Staircase Solutions in Multi-storey Apartment Blocks Based on Wooden Structures', in IOP Conference Series: Materials Science and Engineering, 2019, vol. 603, no. 2.

[16] J. Scheck and B. Gibbs, 'Impacted lightweight stairs as structure-borne sound sources', Appl. Acoust., vol. 90, 2015.

[17] T. Herzog, J. Natterer, R. Schweitzer, M. Volz, and W. Winter, Timber Construction Manual. Birkhäuser, 2013.

[18] M. N. Giannakos, K. Chorianopoulos, M. Ronchetti, P. Szegedi, and S. D. Teasley, 'Video-Based Learning and Open Online Courses', Int. J. Emerg. Technol. Learn., vol. 9, no. 1, pp. 4-7, 2014.

[19] R. McGreal, D. G. Sampson, N.-S. Chen, Kinshuk, M. S. Krishnan, and R. Huang, 'The Open Educational Resources (OER) Movement: Free Learning for All Students', in 2012 IEEE 12th International Conference on Advanced Learning Technologies, 2012, pp. 748-751.

[20] T. Traphagan, J. V. Kucsera, and K. Kishi, 'Impact of Class Lecture Webcasting on Attendance and Learning', Educ. Technol. Res. Dev., vol. 58, no. 1, pp. 19-37, Feb. 2010.

[21] O. Poquet, L. Lim, N. Mirriahi, and S. Dawson, 'Video and Learning: A Systematic Review (2007-2017)', in $A C M$ International Conference Proceeding Series, 2018, pp. 151160 .

[22] R. Verleur, A. Heuvelman, and P. W. Verhagen, 'Trigger Videos on the Web: Impact of Audiovisual Design', Br. J. Educ. Technol., vol. 42, no. 4, pp. 573-582, Jul. 2011. 